\title{
Pristimerin attenuates sepsis-induced lung injury by regulating nuclear factor kappaB/high-mobility group box 1 pathway
}

\author{
Xiao Wang ${ }^{1 *}$, Lei Huang ${ }^{2}$, Peng $\mathbf{L i}^{3}$ \\ ${ }^{1}$ Department of Integrated Traditional Chinese and Western Medicine, ${ }^{2}$ Department of Intensive Care Unit, ${ }^{3}$ Department of \\ Respiration, Tianjin Occupational Diseases Prevention and Therapeutic Hospital (Tianjin Workers' Hospital), Tianjin 300011, \\ China
}

*For correspondence: Email: 362550125@qq.com; Tel: 0086-022-24334059

Sent for review: 11 November 2019

Revised accepted: 25 May 2020

\begin{abstract}
Purpose: To determine the effect of pristimerin on sepsis-induced lung injury, and the underlying mechanism of action.

Methods: Lung injury was established in mice via induction of sepsis through cecal ligation and puncture (CLP). The effect of pristimerin was evaluated based on lung wet/dry weight and $\mathrm{PaO}_{2} / \mathrm{FiO}_{2}$ ratios. Lung tissue was subjected to immunohistochemical and histopathological analyses, as well as Western blotting. Furthermore, the serum levels of inflammatory mediators were determined.

Results: Pristimerin reversed the altered lung wet/dry weight ratio and $\mathrm{PaO}_{2} / \mathrm{FiO}_{2}$ ratio in the lung, and also reduced lung injury score, relative to CLP group $(p<0.05)$. Moreover, it suppressed nucleocytoplasmic translocation of high mobility group protein B1 (HMGB1) in lung tissue. Serum levels of inflammatory mediators and expression levels of inducible nitric oxide synthase and nuclear factorkappaB p65 were significantly reduced by pristimerin $(p<0.05)$.

Conclusion: Pristimerin ameliorates sepsis-induced lung injury by inhibiting HMGB1/NF-KB. Thus, this compound has a potential for clinical application in the management of lung injury.
\end{abstract}

Keywords: Pristimerin, Sepsis, Lung injury, Inflammatory mediators, HMGB1

\begin{abstract}
This is an Open Access article that uses a fund-ing model which does not charge readers or their institutions for access and distributed under the terms of the Creative Commons Attribution License (http://creativecommons.org/licenses/by/4.0) and the Budapest Open Access Initiative (http://www.budapestopenaccessinitiative.org/read), which permit unrestricted use, distribution, and reproduction in any medium, provided the original work is properly credited.

Tropical Journal of Pharmaceutical Research is indexed by Science Citation Index (SciSearch), Scopus, International Pharmaceutical Abstract, Chemical Abstracts, Embase, Index Copernicus, EBSCO, African Index Medicus, JournalSeek, Journal Citation Reports/Science Edition, Directory of Open Access Journals (DOAJ), African Journal Online, Bioline International, Open-J-Gate and Pharmacy Abstracts
\end{abstract}

\section{INTRODUCTION}

Sepsis, a systemic inflammation due to infection, is associated with multiple organ dysfunction, and it is a leading cause of death in intensive care units [1]. Globally, about 19 million patients suffer from sepsis annually. One of the major complications of sepsis is acute lung injury [2]. The prognosis of patients with sepsis-induced lung injury is very poor, and high mortality often occurs. Therefore, there is need for therapeutic interventions for lung injury [3]. In sepsis, inflammation is mediated by altered expression of high-mobility group box 1 (HMGB1) which is also involved in the pathogenesis of lung injury [4]. High-mobility group box 1 (HMGB1) which is secreted by monocytes and macrophages, is a late mediator of inflammation in sepsis [5]. It induces the production of proinflammatory cytokines by activating the nuclear factor-kappaB 
(NF- $\square$ B) pathway [6]. Studies have shown that $\mathrm{NF}-\kappa \mathrm{B}$ participates in the pathogenesis of lung injury by increasing the expressions of cytokines that contribute to systemic inflammation by stimulating the acetylation of the p65 subunit [7].

Alternative medicines for the management of chronic disorders have continued to receive a lot of attention. Several natural medicines have shown potential for the treatment of lung injury. Pristimerin is a triterpenoid isolated from Celastraceae [8]. It is used in traditional Chinese medicine for treating inflammatory and autoimmune disorders and tumours [9]. Pristimerin exerts strong antioxidant effects by inhibiting inducible nitric oxide synthase (iNOS), thereby reducing nitric oxide (NO) level [10]. This results in anti-inflammatory and hepatoprotective effects [11]. Moreover, pristimerin inhibits the inflammatory cascade, and reduces NF- $\mathrm{KB}$ levels [12]. The present study determined the effect of pristimerin on sepsis-induced lung injury in mice.

\section{EXPERIMENTAL}

\section{Animals}

Male albino mice weighing $20-25 \mathrm{~g}$, were purchased from Shanghai Medical College, China. The mice were acclimatised under a 12-h day/12-h night light cycle with $60 \pm 5 \%$ humidity at $24 \pm 3^{\circ} \mathrm{C}$, according to the guidelines of Association for the Assessment and Accreditation of Laboratory Animal Care International (AAALAC) [13]. All experimental procedures involving animals were approved by the Institutional Animal Ethics Committee of Guizhou Provincial People's Hospital, China (IAEC/GPPH/2017/04).

Lung injury was induced via sepsis, which was in turn induced by cecal ligation and puncture $(C L P)$. The mice were fasted overnight and anesthetised with pentobarbital at a dose of 30 $\mathrm{mg} / \mathrm{kg}$ intraperitoneally, i.p. The cecum was subjected to laparotomy. An 18-gauge needle was used to puncture the region below the ileocecal valve twice, to ligate the cecum. The abdominal cavity was closed after returning the caecum. In the sham-operated group, only laparotomy was performed. The mice were divided into control, CLP, and two pristimerin groups given the drug at a dose of 10 or $100 \mathrm{mg} / \mathrm{kg}$ i.p, $30 \mathrm{~min}$ after surgery.

\section{Determination of $\mathrm{PaO}_{2} / \mathrm{FiO}_{2}$ ratio}

The mice were anesthetised 1 day after CLP, and arterial blood samples were subjected to
$\mathrm{PaO}_{2}$ analysis. The oxygenation index was expressed in terms of $\mathrm{PaO}_{2} / \mathrm{FiO}_{2}$ ratio.

\section{Histopathological examination of lung tissue}

The mice were euthanised, and their lungs were excised and fixed in formalin (10\%) for 3 days. Sections of the pulmonary lobes were seeded in paraffin and sectioned to 3- $\mu \mathrm{m}$ thick slices using a microtome. The sections were stained with haematoxylin and eosin. Infiltration of inflammatory cells, necrosis, interstitial oedema and haemorrhage were determined using a scale ranging from $0-3$.

\section{Immunohistochemical analysis}

The $3-\mu m$ thick sections of lung tissue were blocked for 10 min in $3 \% \mathrm{H}_{2} \mathrm{O}_{2}$. An anti-HMGB1 $(1: 1000)$ antibody was then added, followed by visualisation with 3,3'-diaminobenzidine and counter-staining with Mayer's haematoxylin.

\section{Determination of inflammatory mediators}

The serum levels of HMGB1, interleukin (IL)-6, and tumour necrosis factor (TNF)- $\alpha$ were determined using enzyme-linked immunosorbent assay according to the manufacturer's instructions. Serum nitrite concentration was determined using a nitrite/nitrate colorimetric assay kit.

\section{Western blotting}

Total protein from lung tissue homogenate was resolved with $8 \%$ sodium dodecyl sulphatepolyacrylamide gel electrophoresis, and transferred to a nitrocellulose membrane. The membrane was blocked in $\mathrm{H}_{2} \mathrm{O}_{2}$ and incubated for $1 \mathrm{~h}$ with primary antibodies against $\alpha$-tubulin, iNOS, NF-kB p65, and $\beta$-actin. Thereafter, the membrane was washed twice with phosphatebuffered saline and incubated for $30 \mathrm{~min}$ with horseradish peroxidase-conjugated goat antimouse IgG. A chemiluminescence kit was used to develop the bands, the intensity of which was quantified with densitometric analysis.

\section{Statistical analysis}

Data are presented as mean \pm standard deviation (SD) $(n=6)$. Statistical analysis was performed using one-way analysis of variance with Dunnett's post hoc test. All statistical analyses were performed using Prism software (ver. 6.1; GraphPad Software, Inc., La Jolla, CA, USA). Values of $p<0.05$ were considered indicative of statistical significance. 


\section{RESULTS}

Pristimerin reduced lung wet/dry weight ratio, but increased $\mathrm{PaO}_{2} / \mathrm{FiO}_{2}$ ratio

The lung wet/dry weight ratio was increased, while the $\mathrm{PaO}_{2} / \mathrm{FiO}_{2}$ ratio was decreased in the CLP group, when compared to the control group (Figure 1). The lung wet/dry weight ratio was significantly reduced, while the $\mathrm{PaO}_{2} / \mathrm{FiO}_{2}$ ratio was significantly increased $(p<0.01)$ by pristimerin.
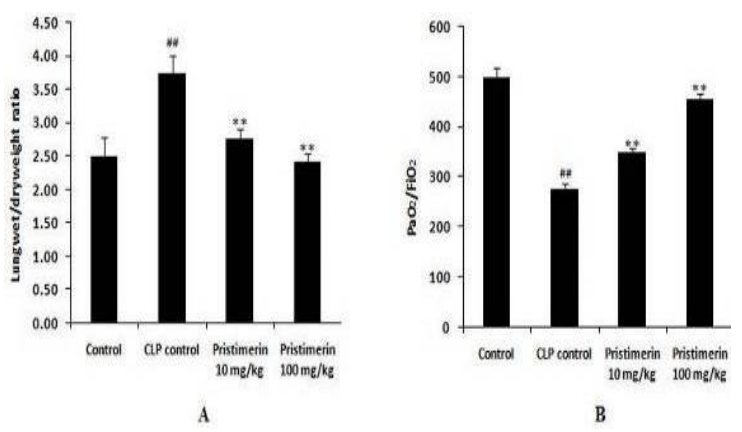

Figure 1: Effect of pristimerin on lung wet/dry weight and $\mathrm{PaO}_{2} / \mathrm{FiO}_{2}$ ratios in mice with sepsis-induced lung injury. Data are mean \pm SD $(n=6) ;{ }^{\#} p<0.01$ vs. control group; ${ }^{* *} p<0.01$ vs. cecal ligation and puncture (CLP) group

\section{Pristimerin lowered sepsis-induced increase in lung injury score}

Lung histology was significantly altered in the CLP group, when compared to the control group (Figure 2). Lung injury scores (haemorrhage, necrosis, oedema, and neutrophil infiltration) were significantly increased in the CLP group, relative to the control group. However, these increases were attenuated by pristimerin.
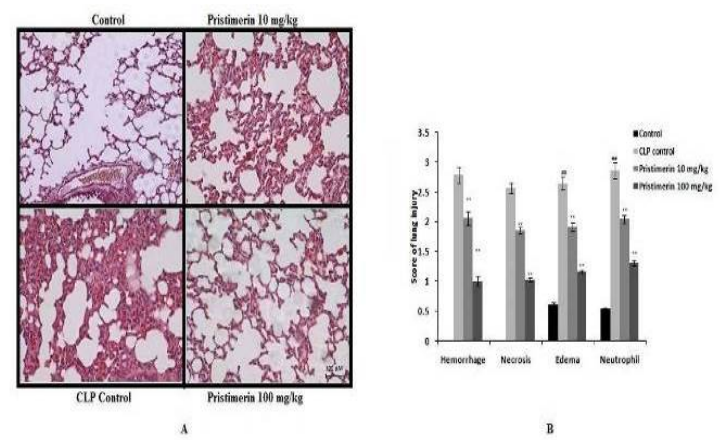

Figure 2: Effect of pristimerin on lung histopathology in mice with sepsis-induced lung injury. A: Haematoxylin and eosin staining (x100); B: lung injury scores. Data are mean \pm SD $(n=6) ;{ }^{\#} p<0.01$ vs. control group; ${ }^{* *} p<0.01$ vs. CLP group

\section{Pristimerin reduced the expression of HMGB1}

Nucleocytoplasmic translocation of HMGB1 in lung tissue was suppressed by pristimerin, relative to the CLP group (Figure 3).

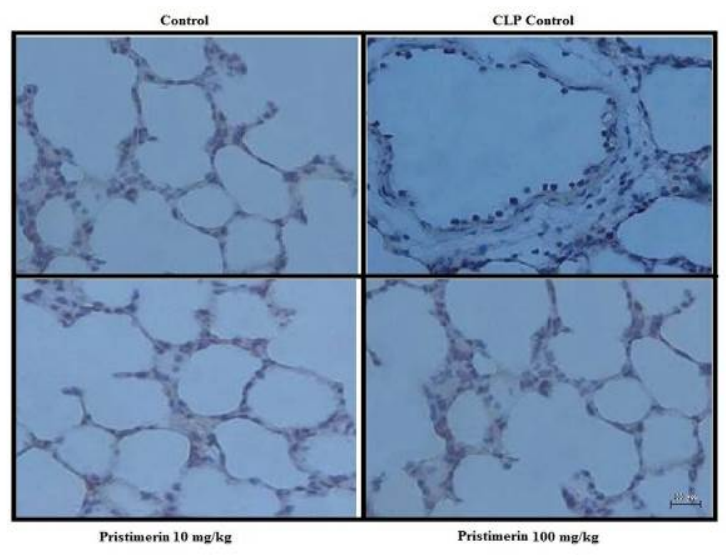

Figure 3: Effect of pristimerin on the expression of HMGB1 in the lung tissue of mice with sepsis-induced lung injury: results of immunohistochemical analysis

\section{Pristimerin modulated the levels of inflammatory mediators}

Figure 4 shows that the serum levels of HMGB1, TNF- $\alpha$, IL-6, and
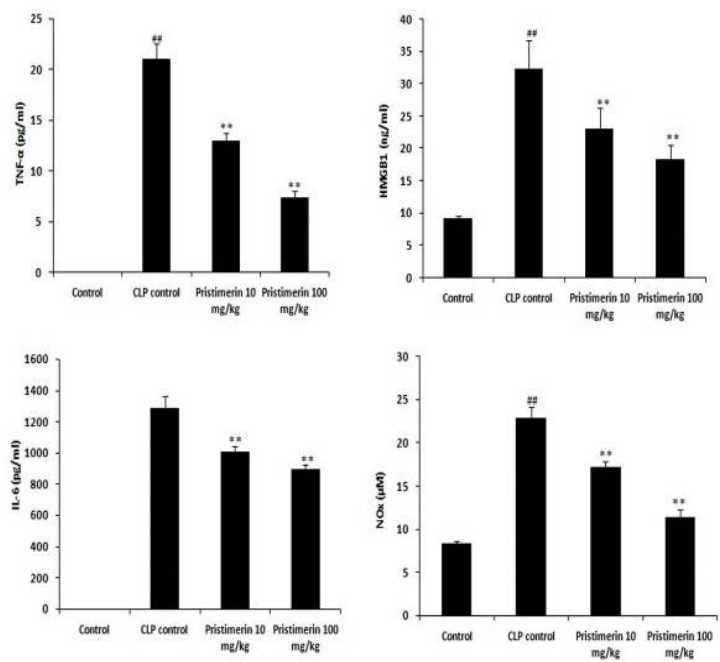

Figure 4: Effect of pristimerin on the serum levels of inflammatory mediators in mice with sepsis-induced

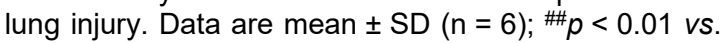
control group; ${ }^{* *} p<0.01$ vs. CLP group

\section{Pristimerin reduced the expressions of iNOS and NF-KB p65}

The expressions of iNOS and NF-KB p65 were significantly increased in the lung tissue of the

Trop J Pharm Res, June 2020; 19(6): 1169 
CLP group, relative to the control group ( $p<$ 0.01). However, this effect was significantly reversed by pristimerin ( $p<0.01$; Figure 5).
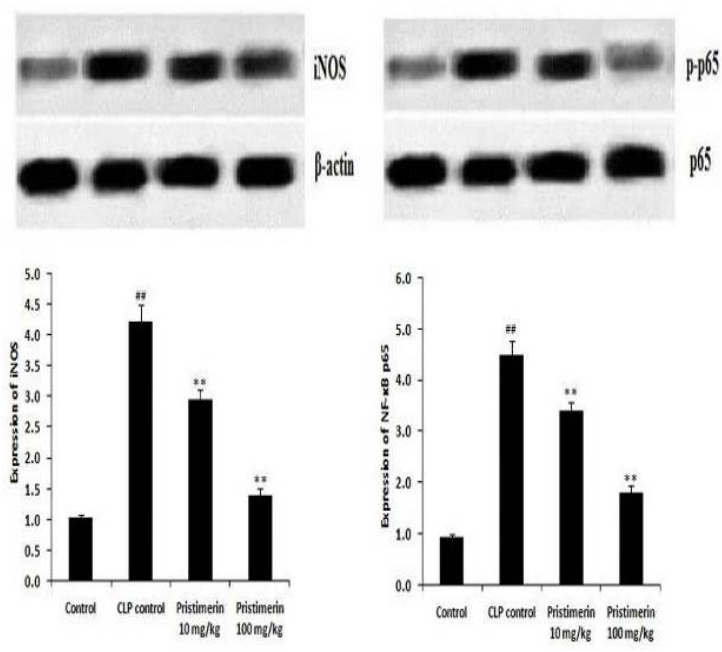

Figure 5: Effect of pristimerin on the expressions of inducible nitric oxide synthase (iNOS) and nuclear factor kappa B (NF-kB) p65 in lung tissue of mice with sepsis-induced lung injury. Data are mean $\pm S D$ $(\mathrm{n}=6) ;{ }^{\# \#} p<0.01$ vs. control group; ${ }^{* *} p<0.01$ vs. CLP group

\section{DISCUSSION}

The present study evaluated the protective effect of pristimerin against sepsis-induced lung injury by determining lung wet/dry weight ratio, $\mathrm{PaO}_{2} / \mathrm{FiO}_{2}$ ratio, and serum levels of inflammatory mediators.

The expressions of iNOS and inflammatory cytokines are induced by NF-kB. Inhibitor of kappaB is translocated to the nucleus in response to various stimuli, where it induces inflammation and cell adhesion and proliferation [13]. It is known that NF-KB regulates innate immune response [14]. In this study, pristimerin decreased serum levels of iNOS, TNF- $\alpha$, and IL6 , and significantly decreased NF-KB level in the lung tissue of mice with sepsis-induced lung injury.

Pristimerin attenuated haemorrhage, necrosis, oedema and neutrophil infiltration in mice with sepsis-induced lung injury, in agreement with a previous report [15]. Studies have shown that HMGB1 acts as a late mediator of inflammation in sepsis-induced lung injury [16]. In the present study, pristimerin suppressed the nucleocytoplasmic translocation of HMGB1 in the lung tissue of mice with sepsis-induced lung injury.

\section{CONCLUSION}

Pristimerin ameliorates sepsis-induced lung injury in rats by inhibiting HMGB1 and NF-KB. Therefore, pristimerin may be useful clinically for the management of lung injury. However further investigations are required to ascertain this.

\section{DECLARATIONS}

\section{Acknowledgement}

We thank Beijing Union Medical Foundation Rui E (ruiyi) Emergency Medical Research Special Fund for funding (no. re2016-005).

\section{Conflict of interest}

No conflict of interest is associated with this work.

\section{Contribution of authors}

We declare that this work was done by the authors named in this article and all liabilities pertaining to claims relating to the content of this article will be borne by the authors. XW designed and supervised the protocol and prepared the manuscript, $\mathrm{LH}$ and $\mathrm{PL}$ performed the study protocol and statistical analysis of presented work.

\section{Open Access}

This is an Open Access article that uses a funding model which does not charge readers or their institutions for access and distributed under the terms of the Creative Commons Attribution License (http://creativecommons.org/licenses/by/ 4.0) and the Budapest Open Access Initiative (http://www.budapestopenaccessinitiative.org/rea d), which permit unrestricted use, distribution, and reproduction in any medium, provided the original work is properly credited.

\section{REFERENCES}

1. Martin GS. Sepsis, severe sepsis and septic shock: Changes in incidence, pathogens and outcomes. Exp Rev Anti-Infect Ther 2012; 10(6): 701-706.

2. Shankar-Hari M, Rubenfeld GD. Understanding long-term outcomes following sepsis: implications and challenges. Curr Infect Dis Rep 2016; 18(11): 37.

3. Perl M, Lomas-Neira J, Venet F, Chung C-S, Ayala A. Pathogenesis of indirect (secondary) acute lung injury. Exp Rev Resp Med 2011; 5(1): 115-126.

4. Passali D, Kern E, Lei Chen R, Bellussi L. High mobility group box 1 (HMGB 1): a new protein in the

Trop J Pharm Res, June 2020; 19(6): 1170 
pathogenesis of ENT inflammatory and infectious diseases. Acta Otorhinolaryngolltalica 2012; 32(1): 4647.

5. Chorny A, Delgado M. Neuropeptides rescue mice from lethal sepsis by down-regulating secretion of the lateacting inflammatory mediator high mobility group box 1. Am J Path 2008; 172(5): 1297-1307.

6. Li G, Wu X, Yang L, He Y, Liu Y, Jin X, Yuan H., TLR4mediated NF-KB signaling pathway mediates HMGB1induced pancreatic injury in mice with severe acute pancreatitis. Int J Mol Med 2016; 37(1): 99-107.

7. Kumar R, Yong QC, Thomas CM. Do multiple nuclear factor kappa $B$ activation mechanisms explain its varied effects in the heart? Ochsner J 2013; 13(1): 157-165.

8. Paz TA, dos Santos VA, Inácio MC, Pina ES, Pereira AM, Furlan M. Production of the quinone-methide triterpene maytenin by in vitro adventitious roots of Peritassa campestris (Cambess.) A.C.Sm. (Celastraceae) and rapid detection and identification by APCI-IT-MS/MS. Biomed Res Int 2013; 2013: 485837.

9. Tong L, Nanjundaiah SM, Venkatesha SH, Astry B, Yu H, Moudgil KD. Pristimerin, a naturally occurring triterpenoid, protects against autoimmune arthritis by modulating the cellular and soluble immune mediators of inflammation and tissue damage. Clin Immunol 2014; 155(2): 220-30.

10. El-Agamy DS, El-Harbi KM, Khoshhal $S$, et al., Pristimerin protects against doxorubicin-induced cardiotoxicity and fibrosis through modulation of Nrf2 and MAPK/NF-KB signaling pathways. Cancer Manag Res 2018; 11: 47-61.

11. El-Agamy DS, Shaaban AA, Almaramhy HH, Elkablawy $S$, Elkablawy MA. Pristimerin as a novel hepatoprotective agent against experimental autoimmune hepatitis. Front Pharmacol 2018; 9: 292.

12. Kim HJ, Park GM, Kim JK. Anti-inflammatory effect of pristimerin on lipopolysaccharide-induced inflammatory responses in murine macrophages. Arch Pharm Res. 2013; 36(4): 495-500.

13. Guide for the Care and Use of Laboratory Animals: Eighth Edition Committee for the Update of the Guide for the Care and Use of Laboratory Animals; National Research Council. 2010; ISBN: 0-309-15401-4.

14. Park MH, Hong JT. Roles of NF-KB in cancer and inflammatory diseases and their therapeutic approaches. Cells 2016; 5(2): 15.

15. Lawrence $T$. The nuclear factor NF-KB pathway in inflammation. Cold Spring Harbor Perspect Biol 2009;1(6):a001651.

16. Hirano $Y$, Aziz $M$, Yang $W$ - $L$, Ochani $M$, Wang $P$. Neutralization of osteopontin ameliorates acute lung injury induced by intestinal ischemia-reperfusion. Shock (Augusta, GA) 2016; 46(4): 431-438.

17. Yang $H$, Tracey KJ. Targeting HMGB1 in inflammation. Biochim Biophys Acta 2010; 1799: 149-156. 